\title{
Research on urban intelligent growth--taking Karamay and Wellington as examples
}

\author{
Zhedong $\mathrm{Hu}$ \\ North China Electric Power University (Baoding), Hebei, China \\ Corresponding author e-mail: 2158827802@qq.com
}

\begin{abstract}
The growth of urban intelligence relies on the deep integration of economic prosperity, environmental sustainability and social equity, so the establishment of a rational urban intelligence evaluation model has far-reaching impact on the development of a city. This paper evaluates the development of city intelligence by establishing the SGL evaluation model based on analytic hierarchy Process (AHP). Firstly, according to the principle of intelligent growth and three sustainable "E", the paper constructs the Urban Intelligence Index which includes 3 aspects, such as economic prosperity, social equity and environment sustainability, and obtains SGL evaluation model by analytic hierarchy process. According to the future intelligent curve of Karamay and Wellington, the intelligent status of two cities is obtained by using SGL evaluation model, and then the maneuverability of the model is verified.
\end{abstract}

Key words: Analytic hierarchy process; SGL Evaluation model; Karamay; Wellington.

\section{BACKGROUND}

Sustainable development is an important global issue, it is an economic growth model that emphasizes long-term development. Smart growth is an urban planning theory that originated in 1990's to curb continued urban sprawl and reduce the loss of farmland surrounding urban centers. Many communities are implementing smart growth initiatives to consider long range, sustainable planning goals. Smart city construction starts from the city intelligence, smart growth is about helping every town and city become a more economically prosperous, socially equitable, and environmentally sustainable place to live in. Smart growth pays attention to three aspects of sustainable development: economic boom, social equality and environmental sustainability. The task is more important than ever because the world is rapidly urbanizing. It is project that 2.5 billion people will join the world's urban population. Therefore, urban construction is becoming more and more important to ensure that people have access to equitable and sustainable homes, resources and jobs.

\section{SGL EVALUATION MODEL}

The selection of our indicators for smart growth is based on 3E'sprinciples and 10 principles.3E's principles refers to Economically prosperous(EP), socially Equitable(SEQ), and Environmentally sustainable(ESU). Namely, keep economy sustained and steady, guarantee the right to fair and ensure environment protection if the government adopt smart growth strategy.

According to the principle of $3 \mathrm{E}$ and the 10 principles of development, we have obtained the evaluation and the weight of construction level of the smart city through the analytic hierarchy (AHP). 


\section{Basic Principle}

In many decision-making, the weight of each objective has important influence on the analysis result, but the determination of the weight is difficult. The basis of analytic hierarchy process is that the target's stratification and the importance of each target in the same level can get compared, so that the weight of each target is operable.

\section{Basic steps:}

\section{Establish a Hierarchical Model}

Firstly, classification of the factors involved is generally divided into: one is the target layer, which represents the purpose of solving the problem. The second is the criterion layer, which indicates whether the target can be achieved. The 30 measures layer refers to the plan and method to achieve the goal. Then, from the target to the measures, the direct links of various factors are arranged at different levels from top to bottom, thus forming a hierarchical structure diagram.

TABLE 1. Evaluation index and weight of intelligent city construction

\begin{tabular}{|c|c|c|c|c|}
\hline \multirow[b]{2}{*}{ Target Layer } & \multirow[b]{2}{*}{ Rule Layer } & \multirow[b]{2}{*}{ Index Layer } & \multicolumn{2}{|c|}{ The weight of index layer } \\
\hline & & & $\begin{array}{l}\text { Relative to the } \\
\text { rule layer weight }\end{array}$ & $\begin{array}{c}\text { Rank of } \\
\text { importance }\end{array}$ \\
\hline \multirow{15}{*}{$\begin{array}{l}\text { Smart growth } \\
\text { level A }\end{array}$} & \multirow{5}{*}{$\begin{array}{l}\text { Economically } \\
\text { prosperous B1 }\end{array}$} & GDP C11 & 0.4462 & 1 \\
\hline & & CPI C12 & 0.0769 & 15 \\
\hline & & The growth rate of GDP C13 & 0.1538 & 12 \\
\hline & & Gross social product $\mathrm{C} 14$ & 0.2308 & 8 \\
\hline & & Total foreign trade C15 & 0.3846 & 3 \\
\hline & \multirow{5}{*}{$\begin{array}{l}\text { Environmental-ly } \\
\text { sustainable B2 }\end{array}$} & Natural resources C21 & 0.4000 & 2 \\
\hline & & $\begin{array}{l}\text { Environmental management } \\
\text { results } \mathrm{C} 22\end{array}$ & 0.1250 & 13 \\
\hline & & $\begin{array}{l}\text { Pollution levels in the past } \\
\text { and present } \mathrm{C} 23\end{array}$ & 0.1875 & 10 \\
\hline & & Density of population C24 & 0.3125 & 6 \\
\hline & & Land area per capital C25 & 0.3750 & 4 \\
\hline & \multirow{5}{*}{ Socially equitable B3 } & Engel coefficient C31 & 0.2356 & 7 \\
\hline & & Road area per capital C32 & 0.1047 & 14 \\
\hline & & $\begin{array}{c}\text { Urban basic medical } \\
\text { insurance coverage C33 }\end{array}$ & 0.3141 & 5 \\
\hline & & $\begin{array}{l}\text { The per capita living area of } \\
\text { urban residents } C 34\end{array}$ & 0.1885 & 9 \\
\hline & & $\begin{array}{c}\text { Registered urban } \\
\text { unemployment rate C35 }\end{array}$ & 0.1571 & 11 \\
\hline
\end{tabular}

TABLE 2. The order of importance of each factor

\begin{tabular}{|c|c|c|}
\hline Rank & Level & Colour \\
\hline $1-3$ & very important & \\
\hline $4-7$ & more important & \\
\hline $8-11$ & important & \\
\hline $12-15$ & general \\
\hline
\end{tabular}

Taking the calculation process of B layer index relative to the weight of A layer as an example, the determination process of the weight is described in detail, including the following three steps:

Normalization of each column vector of $\mathrm{A}$ 


$$
\widetilde{w}_{i j}=\frac{a_{i j}}{\sum_{i=1}^{n} a_{i j}}, i=1,2,3 \ldots .
$$

$\widetilde{\mathrm{w}}_{\mathrm{ij}}:$ Sum over each row $\widetilde{w}_{i}=\sum_{j=1}^{n} \widetilde{w}_{i j}$

$\widetilde{\mathrm{w}}_{\mathrm{i}}$ : Normalization $w_{i}=\frac{\widetilde{w}_{i}}{\sum_{i=1}^{n} \widetilde{w}_{i}}$,

Calculate in turn we can get $\bar{w}=\left[w_{1}, w_{2}, w_{3}\right]^{T}=[0.25,0.4375,0.3125]^{T}$

Normalize $\overline{\mathrm{w}}$ we can get the weight of $\mathrm{B}$ layer factor on $\mathrm{A}$.

Calculate the maximum eigenvalue of the judgment matrix.

Ran MATLAB program, the judgment matrix of A minus B is set to A., type command $\lambda=\operatorname{eig}(\mathrm{A})$, The running result is the eigenvector of $A$. To determine the maximum eigenvector. $\lambda \max =3.065$.

\section{Consistency check}

For each pair comparison matrix, the maximum characteristic root and corresponding eigenvector are calculated, and consistency test is made by using the consistency index. If the test passes, the eigenvector is the weight vector. If not, reconstruct the contrast matrix.

TABLE 3. Index weight consistency test.

\begin{tabular}{|c|c|c|c|c|c|c|}
\hline matrix & $\lambda \mathbf{m a x}$ & $\mathbf{n}$ & $\mathbf{C I}$ & $\mathbf{R I}$ & $\mathbf{C R}$ & Consistency Test. \\
\hline A-B & 3.065 & 5 & 0.0365 & 0.58 & 0.06 & Through \\
\hline B1-C & 5.071 & 5 & 0.01775 & 1.12 & 0.0158 & Through \\
\hline B2-C & 5.058 & 5 & 0.0145 & 1.12 & 0.0129 & Through \\
\hline B3-C & 5.046 & 5 & 0.0115 & 1.12 & 0.0103 & Through \\
\hline
\end{tabular}

Calculate the consistency index of judgment matrix and verify its consistency.

$C . I .=\frac{\lambda_{\max }-n}{n-1}=\frac{3.065-3}{3-1}=0.0365<0.1$

Generation into the formula:

$\mathrm{C} . \mathrm{R} .=\frac{C_{.} .{ }_{\text {. }}}{R_{.} .}=\frac{0.03}{0.58}=0.06<0.1$

The CR of each judgment matrix is less than 0.1 , which is tested by consistency.

According to the above steps, we calculate the weight of the c-layer index relative to the B layer, perform the consistency test, summarize the results in table 1 and get the SGL evaluation formula:

$S G L=\alpha E P L+\beta E S L+\gamma S E L$

TABLE 4. Weight Combinations

\begin{tabular}{|c|c|c|c|}
\hline Urbanization Level & EPL Weight & ESL Weight & SEL Weight \\
\hline & & & 0.200 \\
Developed city & 0.400 & 0.400 & 0.334 \\
Developing city & 0.333 & 0.333 & 0.400 \\
\hline
\end{tabular}

TABLE 5. Smart Growth grading standards

\begin{tabular}{|c|c|c|}
\hline grade & value & Qualitative evaluation \\
\hline I & $>0.75$ & Excellent \\
\hline II & $0.50-0.75$ & Good \\
\hline III & $0.25-0.5$ & Moderate \\
\hline IV & $<0.25$ & bad \\
\hline
\end{tabular}




\section{THE INTELLIGENT DEVELOPMENT OF KARAMAY AND WELLINGTON}

\section{The current growth plan for karamay}

Karamay is a prefecture-level city under the jurisdiction of xinjiang uygur autonomous region. It is a new industrial city with important national petroleum and petrochemical bases and xinjiang's key construction.

Economic: The first industrial agricultural production in karamay city grew steadily. Industrial production in the second industry is basically stable. Investment in fixed assets of tertiary industry declined.

Social: It is expected to achieve 120 billion yuan of GDP by 2020, with an average annual growth rate of 13 percent. The service industry is growing at an average annual rate of 12 percent, planning for 63 square kilometers of urban construction land and 150 square meters per capita urban construction land. Retail sales of consumer goods reached 9 billion yuan, an average annual growth of 9 percent. The per capita disposable income of urban residents increased in line with the per capita disposable income of farmers and herdsmen.

Environment: Karamay city construction integrated transportation hub, expand the regional hinterland; ecological livable, energy conservation and emission reduction, promote sustainable development.

\section{The current growth plan for wellington}

Wellington is the capital of New Zealand, on the southern tip of New Zealand's north island, with a population of about 450,000. It is the second largest city in New Zealand and is the national political, industrial and financial center of New Zealand.

Economic: The livestock industry in Wellington is the most important industry in the city and the foundation of the economy. The output value of animal husbandry accounts for about $80 \%$ of agricultural output. Tourism is a pillar industry and an important source of income.

Social: Wellington has a complete set of education systems, including primary schools, secondary schools, vocational schools, normal colleges and universities. Social environment, stable political environment.

Environment: It is temperate maritime climate, having beautiful scenery and rich products. Man, and nature coexist in harmony and develop together.

\section{Smart growth trends in the future}

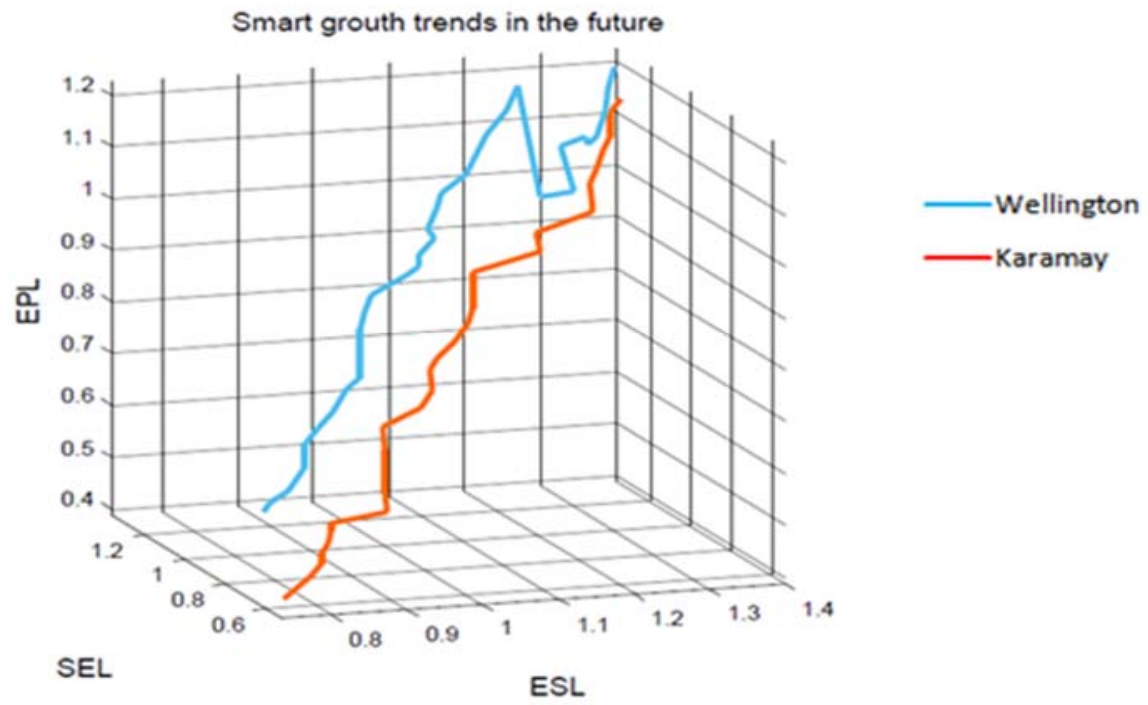

Based on the evaluation model of intelligent city construction and the development plan of two cities, we obtained the following related equations: 
Karamy(China): $S G L=0.333 E P L+0.333 E S L+0.334 S E L=0.572<0.75$

The grows plan is good

Wellington (New Zealand): $S G L=0.400 E P L+0.400 E S L+0.200 S E L=0.684<0.75$

The grows plan is good

\section{CONCLUSION}

Through the establishment of SGL evaluation model based on analytic hierarchy process, making the city intelligent Development more scientific, this paper verifies the practicality of the model by studying the two cities of Karamay and Wellington. It provides some references for the intelligent growth of some cities.

\section{REFERENCES}

1. Jinghua Li, Operation research, Shanghai University of Finance and Economics Press,2012.

2. Saisai Chang, Guanxi Hu, Junwei Kang, Jingyi Lv, Ran Zhao, The Construction of Urban Intelligent Growth Index System Based on Fuzzy Comprehensive Evaluaton,1009-3044(2017)13-0176-03.

3. Linjiao Yan, Comprehensive Evaluation of Intelligent City Construction Level, International book classification number 338.2,2012.

4. Jianchun Chen, Comparision Matrix method and its Application in Fuzzy Level. JOURNAL OF CHENGDU UNIVERSITY OF SCIENCE AND TECHNOLOGY. No.3.1989.

5. Dazhi Li, Dong Xu, Xiaorui Zhang, Peiyi Fan, Smart Growth, FUJIAN COMPUTER,2017.06.066.

6. Hua Wang, Environmental Impact Assessment and Anvironmental Planning and Sustainable Development. JiangSu Environmental Technology, NO4,1998. 